\title{
Antologia Química Portuguesa
}

\section{Afinidades quiescentes versus afinidades divelentes}

Vicente Coelho de Seabra

\section{Da Affinidade.}

§. I6. A acçaठ́ reciproca que exercem os corpos huns fobre os outros he devída a huma lei geral da materia, pela qual todos tendem a unir-fe huns com os outros com maior, ou menor força, fegundo a natureza particular de cada hum; efta lei he aquella, que os Chimicos chamaó Affinidade, e fegundo me parece naó he differente da Attraç̧aó: porém fim efta mefma, como diz Buffon, obrando ou nas maflas grandes, ou nos feos elementos, ou corpos muito pequenos; onde toma o nome de Affimidade. Ora como a attraç̧aó no ponto do contaćto deve obrar fómente na razaó da fuperficie attrahente ( porque nefte cafo a diftancia he nenhuma,

ma, e os elementos faб́ iguaes ) : bem fe vê, que ella deve variar confórme a variedade das fuperficies. Ella pois naó tem lugar fe naó entre os elementos, ou corpos muito pequenos. Efta lei admiravel, de que dependem todos os fenomenos da Natureza, \& da Chimica, póde exiftir entre corpos da mefma, ou de differente natureza : entre eftes chama1e Affinidade de compofífāo, entre aquelles de aggregagaó.

\section{Da Affinidade de Aggregaçaó.}

6. I7 A Affinidade de Aggregaçaó he aquella pela qual os corpos da mefma natureza fe unem, e fórmaó hum todo com as mefmas propriedades, que tinhaó dantes, crefcendo fómente de maffa, e volume. Sirvaó de exemplo tres corpos $a, a, a$, que unindo-fe em razaó delta lei, formaó hum todo $3^{a}$, que tem as mefmas propriedades, que dantes, e fómente augmentou de volume, e de maffa. O gráo defta affinidade he conhecido pela adherencia, ou força, que eftas particulas oppoem á fua defuniaó, ou herencia, ou força, com que eftas particulas fe unem entre fi ; pende a maior, ou menor folidez dos corpos; he claro, que deve haver tantos gráos differentes defta affinidade, quantos faб os differentes gráos de adherencia das particulas do corpo mais folido até á das do corpo mais fluido; ou aeriforme : mas em geral podem-fe reduzir a quatro: $A g$ gregaçá folida, que pertence aos corpos folidos, ou duros, como as pedras, e muitos metaes, \&c. Aggregaçá molle, que pertence aos corpos molles, como a cera \&c. Aggregą̧ắ fluida, como a da agoa, e Mercurio, \&c. emfim Aggregaçáo aeriforme, como a do ar, e em geral a das fubstancias aeriformes. $\mathrm{B}_{2}$ Da

\section{Da Affinidade de Compofiçắ.}

5. 18. A lei pela qual dous corpos $a$, e $b$ de differente natureza fe unem intimamente, refultando defta combinaçaó hum novo corpo $a b$ compofto $\operatorname{de} a, \mathrm{e} b$, he aquella, que fe chama Affinidade decompofí̧̧á : efta lei naó differe da precedente, fe naó por fer entre corpos de diverla natureza: mas para que tenha lugar faó precifas as condiçoens feguintes: 1 . Que entre os corpos combinantes haja manifeftamente efta lei; ha corpos que pela arte naó le unem, fe naó por meio de outros, como a agoa com o oleo: 2 . Que hum delles ao menos efteja no eftado fluido: os corpos folidos naó fe combinaб: : 3. Que aquelles que fe houverem de unir fejaó de differente natureza; fe forem da mefma naó haverá fe naó affinidade de aggregaçaő : ella póde ter lugar entre dous, tres, quatro, e mais corpos todos diverios.

5. 19. Quando ha Afinidade de compofiçaó fuccedem conftantemente os fenomenos feguintes: $\mathbf{I}$. ha mudança de temperatura no tempo da combinaçaó; nós daremos a razaó defte fenomeno, quando tratarmos do calor. 2, o compofto adquire lempre novas propriedades, e differentes daquellas, que tinha cada hum dos corpos antes de fe unirem : as vezes toma propriedades inteiramente contrarias. 3 . Quanto mais deftruida eftá a affinidade de aggregaçá das fubftancias combinantes, tanto mais de prelfa fe executa a affinidade de compofiçaб. 4. Que todos os corpos naó tem entre $f i$ a mefma força, ou gráo de affinidade; logo fómente por meio da oblervaça poderemos determinar o gráo defta forca entre as differentes fubitancias.

5. 20. O gráo de força delta affinidade mede-fe pela

pela difficuldade que fe experimenta em defcombinar os corpos combinados. Efta decompofiçaó faz-le por meio de outros corpos que tephaó mais affinidade com algum dos combinados, do que aquella que eftes tinhaб entre fi: a pratica fómente nos póde enfinar quaes faó aquelles corpos. A affinidade de compofiçá fe divide em Simples, de Intermedio, Electiva, Dobrada, e Reciproca.

\footnotetext{
a Departamento de Quimica, Faculdade de Ciências e Tecnologia,
} Universidade de Coimbra. 
๒. 21. A Affinidade de compofiçaó fimples he quando dous, tres, quatro, ou mais corpos differentes fe combinaó, e formaó pela fua uniaó hum novo compofto.

§. 22. A Affinidade de Intermedio, he quando naô havendo entre os corpos, que fe quer unir, huma affinidade manifefta, fervimo-nos d'hum terceiro corpo que tenha affinidade com os primeiros; e affim le combinaó os tres entre fi formando hum novo compofto: por exemplo, fe quizeffemos combinar o corpo a com $b$, e fe entre eftes dous паб houveffe affinidade manifefta;procurariamos hum terceiro $c$, que tivefle affinidade com os dous primeiros; e mifturando-fe todos, teriamos huma combinaçaó, donde refultaria hum novo corpo compolto dos tres $a c b$ : entaó dizemos que a affinidade, ou a combinaçaó de $a \operatorname{com} b, \mathrm{fe}$ fez por intermedio do corpo $c$.

§. 23. Se a hum compofto $a b$ dos dous corpos $a$, e $b$ ajuntarmos hum terceiro $c$, com o qual o corpo $b$ tenha mais affinidade, do que com o corpo $a$; he claro, que $b$ deixará o corpo $a$, e fe combinará $\operatorname{com} c$ formando hum novo compolto $b c$. Elta efpecie de efcolha, que o corpo $b$ teve para deixar $a$, e combinar-fe $\operatorname{com} c$ he, que fe chama $A f f$ nidade Electiva. Por efta fe fazem quafi todas as compofiçoens, e decompofiçoens tanto naturaes, como chimicas, ou artificiaes.

§. 24 .

§. 24. A Affinidade dobrada he quando hum compolto $a b$ dos dous corpos $a$, e $b$, naó póde fer decompofto por hum terceiro $c$, nem por hum quarto $d$ feparadamente, mas unindofe-lhe hum compofto $c d$ do terceiro, e quarto corpo: ha logo huma decompofiçaó mutua. Para concebermos como fuccede efte fenomeno, reprefentaremos eftes compoftos defte modo.

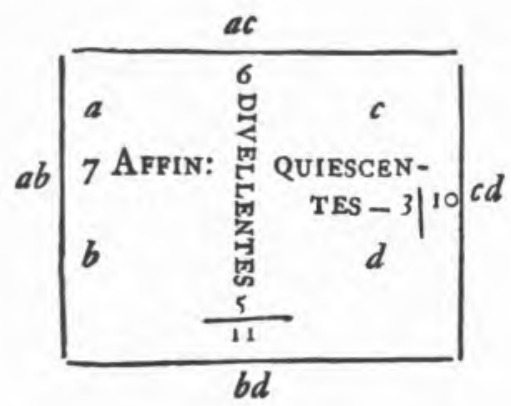

A affinidade que une o corpo $a \operatorname{com} b$, que fuppomos igual a 7 , e a que une o corpo $c$ com $d$, que fuppomos igual a 3 , chamaó-fe affinidades quie/centes: a que tende a unir o corpo $a \operatorname{com} c$, que fuppomos igual a 6 , e a que tende a unir $b$ com $d$, que fuppomos igual a 5 , chamaó-fe affinidades divellentes. Ifto pofto he claro, que eftando - corpo $a$ combinado $\operatorname{com} b \operatorname{com}$ huma força igual a 7 , naó poderá o compofto $a b$ decompor-fe nem pelo corpo $c$ que tem com $a$ fómente 6 de força de affinidade, nem pelo corpo $d$, que tem com $b$ fómente 5 de affinidade; mas fe ao compotto $a b$ unirmos juntamente o corpo $c$, e $d$, ifto he o compofto $c d$; entaó como a fomma II das forças, com que $c$ tende a combinar-fe com $a$; e $d \operatorname{com} b$ he maior,

do

do que a força 7 , que une $a \operatorname{com} b$, haverá duas decompofiçoens, huma do compofto $a b$, e outra do compofto $c d$; e $a$ le combinará com $c$ formando o novo compofto $a c$; e $b$ fe combinará com $d$ formando outro novo compofto $b d$. Eisaqui o que he affinidade dobrada; mas he de advertir, que ella naó póde ter lugar, fe naó quando a lomma das affinidades divellentes for maior, do que a fomma das affinidades quiefcentes. Vejaó-fe as Memorias Chimicas de Fourcroy (r.vol. pag. $308-\mathrm{e}$ 438. )

5. 25. A Affini dade reciproca he quando hum compofto $a b$ he decompofto por hum terceiro corpo $c$, que tinha maior affinidade com hum dos dous componentes, por exemplo $b$; formando hum novo compofto $b c$, e deixando $a$ livre; mas depois de feita a decompofiçaó, o corpo $a$ faz-fe novo decomponente de $b c$, e torna-fe a combinar $\operatorname{com} b$, reproduzindo o antigo compofto $a b$; hauendo repetidas vezes efte jogo 'reciproco. Mas he de notar que o compofto $b c$ naō pode fer decompofto por $a$, fenaó por alguă circunftancia, que faça, com que $a$ tenha com $b$ mais affinidade, que $c$ : o que muitas vezes accontece pelo calor, privaçaó, ou accefto do ar, e phlogifticaçaó \&c. Em todas eftas affinidades ha lempre decompofiçaó, e compofiçắ ao mefmo tempo.

\begin{abstract}
Vicente Coelho de Seabra, Elementos de Chimica(*), (Coimbra, Real Officina da Universidade, 1788), \& 16-25 , pp. 10-15.
\end{abstract}

\section{NOTA BIOGRÁFICA}

Vicente Coelho de Seabra era natural de Vila Rica, capitania de Minas Gerais, no Brasil, onde nasceu em 1764. Graduou-se na Faculdade de Filosofia da Universidade de Coimbra, em 1791, tendo sido logo nomeado demonstrador de Química e Metalurgia do Laboratório Químico da mesma Faculdade. Ainda como estudante, publicou um tratado de química intitulado Elementos de Chimica, oferecido à Sociedade Literária do Rio de Janeiro para uso do Curso de Química. É o primeiro tratado de química em português. Publicado em dois volumes, o primeiro data de 1788, um ano antes do Tratado de Química de Lavoisier (1); o segundo data de 1790.

Além de várias memórias sobre problemas de saúde pública e agricultura, em Portugal, escreveu ainda:

- Dissertação sobre o calor (Coimbra, Real Imprensa da Universidade, 1788);

- Dissertação sobre a fermentação em geral e suas espécies (Coimbra, Real Imprensa da Universidade, 1792);

- Nomenclatura chimica portugueza, franceza e latina; a que se junta o systema de caracteres adaptados a esta Nomenclatura por Hassenfratz e Adet (Lisboa, Officina do Arco do Cego; 1801).

Morreu em março de 1804, quando não contava ainda 40 $\operatorname{anos}(2)$.

(1) A.L. Lavoisier, Traité Élémentaire de Chimie, Paris, 1789.

(2) Bibliografia: - J.A. Simōes de Carvalho, Memória Historica da Faculdade de Philosophia (Coimbra, Imprensa da Universidade, 1872); A.J. Andrade Gouveia, Memórias da Acad. das Sci. de Lisboa, vol. XXI $(1976 / 77)$ pp. 7-35,

(*) Esta obra foi recentemente editada em reprodução fac-similada (edição do Departamento de Química da Faculdade de Ciências e Tecnologia, Universidade de Coimbra, 1985). 